\title{
The Use of Peer Instruction and Flipped Learning to Support Flexible Blended Learning During and After the COVID-19 Pandemic
}

\author{
Chrissi Nerantzi
}

\section{Manchester Metropolitan University, United Kingdom}

\begin{abstract}
This article provides an overview of peer instruction and flipped learning, two active learning approaches, in the context of learning and teaching in higher education and illustrates their relevance during the COVID-19 pandemic. Peer instruction and flipped learning should be considered when designing for flexible learning. These approaches can stimulate learning and create seamless active engagement in fully online and blended settings even when switching between these modes becomes necessary due to developments in this pandemic. This transitioning between fully online and blended, as and when required, is something that is of high importance during these challenging times, especially for campus-based universities as they are keen to secure the smooth running of their programmes under difficult circumstances. This article provides practical advice for course designers, module and programme leaders on how they can utilise peer instruction or flipped learning to maximise student engagement and learning.
\end{abstract}

Keywords: Blended Learning; COVID-19 Pandemic; Flipped Classroom; Peer Instruction; Student Engagement 


\section{Introduction}

During the COVID-19 pandemic, academics in the United Kingdom and around the world had to adjust their practice almost overnight from predominantly campus modules and programmes to fully online or remote ones. This was an emergency measure to secure the continuation of the courses offered by their institutions and enable students to continue their studies. As the immediate future is uncertain with new outbreaks and lockdowns looming, universities are reviewing and rethinking their pedagogical approaches and their offer to come up with strategies that would make their courses safe and stimulating. This is leading to a flurry of changes in the way we teach and support students' learning and the recognition that finding ways to actively and flexibly engage students in the learning process is key. Jessop (2020) acknowledges that there is now the opportunity to re-imagine the pedagogical approaches we use, and calls for action. Fullan et al. (2020) also note that the disruption that has been caused by the pandemic has required quick (re-)thinking and actions to navigate uncertainty. Learning from this experience has the potential to help us re-imagine learning and teaching. Re-imagining requires creativity and innovation. And while creativity is often seen as hazardous and been a casualty of this (Nelson, 2018) more recently and especially since the start of the pandemic we have seen creativity elevated to rescuer (Crawford, 2020). Perhaps Kleon (2012: 137) is right in saying that "when it comes to creative work, limitations mean freedom".

Chickering and Gamson's (1987) literature review concluded that for learning to happen, it needs to be more than just listening. It needs to be active. Therefore, teaching should have a focus on creating opportunities for students to discuss, debate, problem-solve, inquire, in other words to actively participate in the learning process. Penner (1984) suggested that a start could be made by re-thinking the lecture format. That was many years ago. Today, we are still debating the lecture, its role, format, even its relevance and usefulness in the $21^{\text {st }}$ century. Perhaps traditions, perceptions of what is right and appropriate to the role of the academic, discomfort, lack of incentives and understanding have held many academics back (Bonwell and Eison, 1991).

In a Jisc interview, Armellini (2018) argues that "same place, same time is not enough to guarantee quality when the so-called teaching method is actually 'information delivery': the notes of one person copied into the notes of 200 people without going through the brains of anyone. That is highly problematic". Moving part of the learning into an online environment and giving students more control over the pace, path, time, and place of learning is what Bailey, Schneider and Ark (2013, p. 68) referred as blended learning. When we talk about fully online learning we mean the distribution of learning and teaching across online, networked modes without campusbased teaching, and their seamless integration of such experiences within a module and programme (Quality Assurance Agency for Higher Education, 2020). Professor Alejandro Armellini led an institutional change and developed Active Blended Learning (ABL) across the campus-based University of Northampton in consultation with students. ABL has a focus on student engagement and active participation in and outside the classroom, in face-to-face and online settings supported by tutors, aiming to create a seamless learning experience and blending modes of active learning while

International Journal of Management and Applied Research, 2020, Vol. 7, No. 2 
also allowing flexibility to academics to adopt $\mathrm{ABL}$ in the way that will work in their context and their students (Armellini, 2019).

In this paper, fully online and blended modes of active learning are considered. Modes that will help practitioners and their institutions use the campus, facilities and resources in secure socially distanced ways, utilising the technological infrastructure that is in place to support remote learning and teaching away from the campus. Flexibility will be key; being prepared to switch rapidly between blended and fully online learning and teaching if and when required, as this pandemic is far from over.

Since the start of the COVID-19 pandemic, the terms "emergency remote teaching", and "temporary online pivot" (Nordmann et al., 2020) are mentioned in academic conversations and publications around learning and teaching and curriculum design and their transition and conversion to online modes of learning and teaching. Such terms illuminate the disruption caused by this pandemic across the higher education sector as well as institutional and practitioner driven ideas and propositions put forward that should not be compared to established online courses. Practitioner stories have been published that capture experiences linked to this rapid transition to online learning and teaching, and how they have embraced the challenge, supported and connected with their students in challenging circumstances and turned it into an opportunity for positive changes that may inform future curriculum design interventions and modes of learning and teaching (Qamar, 2020; Telles-Langdon, 2020).

There are a range of pedagogical frameworks that have been designed to support learning using digital technologies in online, open and blended settings, many of them, developed some years ago, are still current and can provide a valuable scaffold for active learning to happen within the curriculum and can also be used to evaluate curriculum interventions (Nerantzi, 2017). Today, the technology is mature enough to support active learning approaches in higher education and consider some of the existing frameworks. A systematic review of a selection of those frameworks (see Appendix) by Nerantzi (2017) revealed the four most important features to make learning happen in such settings are: 1) Facilitator support; 2) Activities, 3) Choice and 4) Community.

Kofinas et al. (2017: 716) acknowledge that "technology innovation has facilitated a number of innovative pedagogies in higher education." Peer instruction and the flipped classroom are two such innovations providing a viable pedagogy for putting learning into an active gear and creating stimulating learning experiences. Both approaches extend learning beyond the physical and live classroom and lay the foundations for seamlessly blended and fully online learning that shifts the responsibility for learning to the students, who engage actively in a range of activities on their own and in collaboration with others in a learning environment where they feel safe and supported by their tutors. Hence, the focus of this paper will be on instilling active learning into students by means of peer instruction and flipped learning as strategies to consider during the COVID-19 pandemic in readiness for the academic year 2020/21 and beyond.

International Journal of Management and Applied Research, 2020, Vol. 7, No. 2 


\section{Active learning and teaching}

While there is a plethora of learning theories, the three main theories of teaching as articulated by Ramsden (2003) are

1. Teaching as telling (passive)

2. Teaching as organising and facilitating (active) and

3. Teaching as making learning possible (self-directed).

The role of the teacher is to help students become autonomous in their learning so that they can continue learning and developing beyond their university studies and throughout life and contribute in positive ways to local communities and society. Therefore, designing and implementing effective teaching strategies that facilitate learning in a supportive environment is really important, an environment that progressively develops independence not dependence.

There is still a tendency to focus primarily on teaching as telling and teachers in higher education often still use didactic strategies, perhaps because teachers feel more in control when using such approaches (Frydenberg, 2012). Teaching as telling was perhaps more relevant and needed, when access to and availability of books and resources was limited (Friesen, 2017). Today, in the information age this is no longer the case. We are flooded by information. However, we still seem to be talking about lectures and seminars, as if learning can or should be compartmentalised, as if information has to be shared through instruction, instruction by the teacher, through telling in class, even if this is not the most effective strategy and the best use of classtime.

We know that learning can happen anytime, anywhere, anyhow. And that students learn best when they are active and immersed in the learning process, when their curiosity is stimulated, when they can ask question and debate in and outside the classroom, when they are supported in this process and feel part of a learning community. There are many things students can learn without needing a teacher (Illich, 1971). We often forget this and cram our programmes full of content leaving little room for personal exploration and discovery. Content delivery is a term frequently used and a concept that often directs the energy of the teacher to preparing materials so that they can deliver content. It will be important to remember that there is no such a thing as content delivery. Knowledge transfer is another term often used. Why would we need universities for this? There is a plethora of resources already out there in a range of formats and media, many made available as open educational resources (OER), open educational practise (OEP) and open access publications. These enable re-use under specific open licenses, often adaptation too. A question to ask ourselves is if we make use of what has been made available by the wider academic community and how we can utilise some of it for our own practice.

We are all immersed in the visual world and often watch, share and create videos not just for entertainment but also for learning and development. Technological advancements have enabled us to not just to consume but also to become digital creators, makers and share openly on the web. Through such activities we connect,

International Journal of Management and Applied Research, 2020, Vol. 7, No. 2 
often via social media. We connect ideas and we connect with each other (Gauntlett, 2018).

A review conducted by Nerantzi (2017) of conceptual and empirical pedagogical frameworks that have been developed to enable learning and teaching supported by digital technologies in a range of blended, fully online and open settings, revealed the following four key characteristics:

1. activities,

2. choice,

3. facilitator support and

4. community.

Recognising the importance of these four characteristics will help teachers redirect their attention from content delivery to planning more interactive and active learning experience for their students. Creating seamless and connected learning opportunities that connect learning pre-, during and post-class supported by technology will be useful to consider (Ehlers, 2020; Scott, 2020).

Active learning enabled through activities and interaction, peer learning and teacher presence and participation in a learning process that is inclusive and recognises that diversity can enrich the learning experience as well as feedback and challenge has been recognised as good practice (Chickering and Gamson, 1987; Gibbs, 2010; Gibbs, 2012). Focusing on what the students do will help teachers think about how they can help their students engage and learn. The teacher's effort in using active learning approaches and activities, such as inquiry-based learning (Problem-Based Learning, Project-Based Learning, the flipped classroom) on its own and with other elements (peer instruction, cooperative, collaborative and team-based learning) will be valuable in this process. Such approaches go back to the concept of learning as an experience (Dewey, 2015). While there is a recognition that learning is messy and the process complex, Bloom (1956) attempted to make order out of chaos and defined the cognitive, affective and kinaesthetic domains of learning and created a taxonomy for the development of higher order thinking skills. His taxonomy is widely used across the education sector, especially where outcomes-based education models are used and can help us scaffold learning.

Peer instruction and flipped learning are explored here as strategies to consider for scaffolding learning and creating active learning opportunities within and beyond the physical or live online classroom. Both approaches can be adapted for campus-based, flexible blended, and fully online programme and module modes. Where classroom is mentioned below, in fully online or blended programmes or modules, this may be seen as time spent with the teacher, synchronously in a live online session using networked technologies.

\section{Peer instruction}

Mazur (1997) is known for developing peer instruction within physics education at Harvard University in the early 90s, when he realised that transmission of information in the physical classroom through lectures didn't help his students learn and engage

International Journal of Management and Applied Research, 2020, Vol. 7, No. 2 
more deeply with specific physics concepts. Much earlier, in the 1960s Problem-Based Learning was developed to respond to unsatisfactory results in Medical Education at McMaster University in Canada that led to a shift of teaching approaches from telling and memorisation towards inquiry and problem-solving (Barrows and Tamblyn, 1980). Peer instruction is an active learning strategy that scaffolds learning, promotes deeper engagement and fosters conceptual understanding through instruction outside the classroom, using peer-to-peer interaction, testing using digital technologies and discussion of answers (Mazur, 1997; Schell and Mazur, 2015; Schell and Butler, 2018).

While it was developed for campus-based courses, it is equally useful for blended and fully online settings. The classroom in this case may be a live or synchronous online session when students and tutor come together, while self-paced or asynchronous activities, before and after the live online session make up the other features of peer instruction. The tutor provides readings and instructs students to access and engage with these before coming to class, therefore helping them prepare for the in-class activities (Schell and Butler, 2018). Peer instruction, as the name suggests, has peer-topeer interactions at its heart where students work together to make sense of questions provided in the form of a quiz and articulate a response to demonstrate their understanding linked to a particular concept. The tutor collects responses and provides feedback and through this process identifies any common difficulties students have and designs the session around these so that they can help students to overcome any challenges, make sense of difficult concepts and move forward in their learning (Schell and Mazur, 2015).

\section{Flipped learning}

The concept of flipped learning has similarities with peer instruction in that both move instruction outside the physical classroom. Flipped learning was developed by Bergmann and Sams (2012) in 2008 in the context of teaching chemistry in Woodland Park High School in Colorado as a result of the challenge they faced in making time to re-teach students who had missed a class. They started recording their lessons and made them available online. They noticed that their students started using them for revising classroom sessions and developed the flipped learning approach that can also be found across higher education practices. Flipped learning aims to move instruction outside of the physical classroom, similarly to peer instruction (Mazur, 1997). In flipped learning, this happens primarily through the use of video resources created by the teacher (Tucker, 2012), freeing up time for collaboration, discussion, problemsolving and application in class to help the teacher provide more targeted support with what students find most troublesome. After class, students are invited to reflect and consolidate their learning before moving forward. Often flipped learning is associated with the use of a video resource provided by the teacher who shares it with students to watch before coming to class (Bergman and Sams, 2012). While flipped learning has been developed to move instruction out of the physical classroom, it works equally well in blended and fully online settings and live or synchronous sessions, while asynchronous activities before and after the live session provide the framework.

International Journal of Management and Applied Research, 2020, Vol. 7, No. 2 
Tucker (2012) highlights that the use of video accompanied by a simple instruction to students to "watch the video" is not enough to make flipped learning effective. He claims that what makes a difference is the integration and use of the videos into the learning process. Therefore, considering specific activities linked to the video is important. Activities will present opportunities for inquiry and personalisation of learning and avoiding watching becoming a passive task. Findlay-Thompson and Mombourguette (2014) highlight the importance for the teacher and students of being familiar with flipped learning to gain the most benefit from it, and that criticality is required from the teacher to identify if flipped learning would be the most suitable approach to use in a particular situation. Students also need to understand the rationale for using flipped learning and see how it will help them in their learning.

Flipped learning has the potential to engage the students outside class. However, when the resources and activities are exclusively designed and prepared by the teacher it may not fully harness the opportunities flipped learning brings for active and deeper engagement in the learning process. Therefore, moving away from students as consumers, tutors should consider engaging students independently or in peer groups in the creation or editing of resources used in flipped learning and therefore deepen their engagement with the subject further. Such an application is found in a study by Nerantzi and Hannaford (2016) in the area of academic development where flipped learning was used with action learning sets tasked with engaging in inquiry into specific learning theories through editing particular Wikipedia pages ahead of class. In class the learning theories were discussed and debated helping students to deepen their understanding further and also identify any aspects of the learning theories they struggled with. The results showed that students enjoyed the authentic nature of the task, felt that they were learning and could support each other in their learning and when faced with technological challenges. Class-time was used to discuss and clarify specific aspects of learning theories that students found difficult to understand. When action learning sets didn't work well together, this seems to have a negative impact on engagement and peer learning.

\section{Flexible blended learning during and after the pandemic}

Higher Education Institutions remained open when the COVID-19 pandemic broke out in the middle of the academic year 2019/20. Transitioning to remote emergency online programme delivery and learning, teaching and assessment happened in a very short time in the UK and around the globe. Existing infrastructure, digital practices and technologies, rapid strategic decision making, staff development and adjustments to curriculum delivery made this rapid shift possible for staff and students. Lessons learnt from this transition are shaping current curriculum plans for the next academic year. Chatzidamianos and Nerantzi (2020) wrote about their observations and reflections during the first few months of the pandemic and note that Positivity, People and Emotions seem to have formed the PPE for learning and teaching in higher education. Staff and students have come together not just as professionals but also as human beings, and have strengthened their relationships to find ways to make learning happen under extremely challenging circumstances. With no vaccine yet in sight, national and local lockdowns and social distancing, track and trace and public health guidance changing constantly higher education needs to be flexible to be able to adjust and

International Journal of Management and Applied Research, 2020, Vol. 7, No. 2 
switch between modes of delivery while also making it manageable for staff. Health and safety and wellbeing of staff and students are paramount to universities.

Resourcefulness and creativity have become more important than ever before and institutions that offer campus-based programmes are seeking solutions that will enable the continuation of study on and off campus using blended approaches. Supporting students' learning is vital under unpredictable circumstances and developments; finding ways to engage students actively in the learning process.

Institutions are considering how this can best happen. They know that going back $100 \%$ to campus-based delivery will not be possible until it is safe. Therefore, institutions are discussing blended learning models that allow, and have, built-in flexibility. This flexibility should enable the switch from blended to fully online if and when needed with minimum disruption, in response to a change in the pandemic, related public health guidance, social distancing, trace and tracking strategies. A flexible blended learning model is therefore envisaged, to be offered fully online if needed and in a blended format if possible.

Not being able to use institutional facilities, such as labs and studios, specialised equipment and spaces, as much as needed or at all creates challenges and constraints especially for more practical subjects and requires resourcefulness, creativity and innovation, which has been demonstrated in the first few months of the pandemic (Bangert et al., 2020). However, it also needs to be acknowledged that even a socially distanced campus and activities could create challenges for staff and students who may be ill or are unable to travel due to family circumstances and responsibilities.

ABL places emphasis on the active engagement of students in their learning process when on campus and online and it provides flexibility in how it can be applied (Armellini, 2018; Armellini, 2019). Therefore, ABL is an attractive approach, especially if a flexible format and the switching from fully online to blended learning is integrated in the curriculum design. $\mathrm{ABL}$ at the time of the pandemic could have lasting impact on how we teach and support students' learning in higher education.

Flipped learning and peer instructions both create opportunities for active learning and therefore could be considered in the context of ABL using digital networked technologies as they enable active engagement in the learning process, individual and peer inquiry and exploration. The below Table 1 may be useful when planning peer instruction or flipped learning.

Table 1: Planning peer instruction or flipped learning

\begin{tabular}{l}
\hline \\
\hline What is this about? \\
What is the anticipated \\
outcome? \\
What activity/ies will \\
the students do? \\
What resources are \\
needed? \\
What challenges did \\
students experience?
\end{tabular}

International Journal of Management and Applied Research, 2020, Vol. 7, No. 2 


\section{Conclusion}

Research shows that flipped learning and peer instruction can be valuable strategies to be considered for actively and deeply engaging students in the learning process across all levels in higher education. Both approaches can be fully adapted and tailored to a range of subject contexts and programmes by practitioners, and work well in the blended and the online classroom supported by networked technology when taking into consideration the four key characteristics of what works in the technology enabled classroom: activities, choice, facilitator support and community (Nerantzi, 2017).

Flipped learning and peer instruction can engage diverse students in inclusive ways, maximising opportunities for self- and peer learning. These approaches can help students establish active learning habits, supported by their tutors but also leading to learner empowerment as they seamlessly integrate self-paced active learning as a vital part of learning outside the physical or live classroom therefore increasing students' own sense of responsibility for their learning and fostering autonomy in a supportive environment. Tutor support and guidance can focus on the particular challenges and concepts students experience with a particular topic, are identified by students and picked up by the tutor through student engagement in the self-paced activities that proceed a live or classroom session. Tutors should pay special attention not just to providing particular resources for self-paced study but to combining these with particular activities to enable deeper engagement with the resources. Furthermore, they should consider engaging students in curating but also co-creating resources for peer instruction and flipped learning. Especially, at the time of the pandemic when institutions and practitioners are seeking to develop curricula in new formats that stimulate active learning in flexible ways, flipped learning and peer instruction should be considered.

\section{Acknowledgements}

The author would like to thank the reviewers for their supportive comments in shaping this article.

\section{References}

1. Armellini, A. (2019), "Putting Learning at the Forefront of Everything: Active Blended Learning as Northampton's New Normal", in: EUNIS 2019, Trondheim, 5th to 7th June 2019, available at: https://www.eunis.org/eunis2019/keynotes/ [Accessed on 1 June 2020].

2. Armellini, A. (2018), "The (large) lecture theatre is dead", Jisc [Online] available at: https://www.jisc.ac.uk/news/the-large-lecture-theatre-is-dead-11-jan-2018 [Accessed on 1 June 2020].

3. Barrows, H.S. and Tamblyn, R.M. (1980) Problem-based learning. An approach to medical education. New York: Springer.

4. Bailey, J., Schneider, C. and Ark, T.V. (2013), Navigating the digital shift. Implementing strategies for blended and online learning, Digital Learning Now! [Online] available at https://www.gettingsmart.com/wp-

International Journal of Management and Applied Research, 2020, Vol. 7, No. 2 
content/uploads/2013/10/DLN-ebook-navigating-PDF.pdf [Accessed on 1 June 2020].

5. Bangert, K., Bates, J., Beck, S.B.M., Bishop, Z.K. , Di Benedetti, M., Fullwood, J. Funnell, A.C., Garrard, A. Hayes, S.A., Howard, T., Johnson, C., Jones, M.R., Lazari, P., Mukherjee, J., Omar, C., Taylor, B.P., Thorley, R.M.S. , Williams G.L. and Woolley, R. (2020), "Remote practicals in the time of Coronavirus, a multidisciplinary approach", engrXiv, https://doi.org/10.31224/osf.io/d7rkg

6. Bergmann, J. and Sams, A. (2012), Flip Your Classroom: Talk To Every Student In Every Class Every Day, USA: International Society for Technology in Education.

7. Bloom, B.S. (1956), Taxonomy of Educational Objectives Handbook: The Cognitive Domain. New York: David McKay.

8. Bonwell, C. C. and Eison, J. A. (1991), Active Learning; Creating Excitement in the Classroom. ASHE-ERIC Higher Education Report, Washington, D.C.: The George Washington University.

9. Chatzidamianos, G. and Nerantzi, C. (2020) "Stripping the layers of the onion" in learning and teaching in HE: positive lessons learned from working during a pandemic", AdvanceHE, [Online] available at: https://www.advancehe.ac.uk/news-and-views/stripping-layers-onion-learning-and-teaching-he [Accessed on 1 July 2020].

10. Chickering, A. W. and Gamson, Z. F. (1987), "Seven Principles for Good Practice in Undergraduate Education”, AAHE Bulletin, pp.2-6.

11. Crawford, P. (2020), "Coronavirus - an outbreak of creativity", Arts and Humanities Research Council, [Online] available at: https://ahrcblog.com/2020/05/22/coronavirus-an-outbreak-ofcreativity/?fbclid=IwAR0agQVM1X3MxHuQyoFzcm8X8htsNjGTglieoY YP41PITVOwOxHA-5fQY [Accessed on 1 June 2020].

12. Dewey, J. (2015), Experience and education. New York: Macmillan Company.

13. Ehlers, U-D. (2020) Future Skills. The future of learning and higher education, translated by Ulf-Daniel Ehlers, Patricia Bonaudo, Laura Eigbrecht Karlsruhe, In: Future Higher Education, Wiesbaden: Springer VS, pp 1-11. https://doi.org/10.1007/978-3-658-29297-3_1

14. Findlay-Thompson, S. and Mombourguette, P. (2014), "Evaluation of a flipped classroom in an undergraduate business course", Business Education \& Accreditation, Vol. 6, No. 1, pp. 63-71.

15. Friesen, N. (2017), The textbook and the lecture. Education in the age of new media, USA: John Hopkins University Press.

16. Frydenberg, M. (2012), “The Flipped Classroom: It's Got to Be Done Right", The Huffington Post [Online] available at: https://bit.ly/2VTX4IV [Accessed on 1 July 2020].

17. Fullan, M. Quinn, J., Drummy, M. and Gardner, M. (2020), Education reimagined: The future of learning, position paper on a paradigm shift for education, A collaborative position paper between New Pedagogies for Deep Learning and

International Journal of Management and Applied Research, 2020, Vol. 7, No. 2 
Microsoft Education. [Online] available at:

https://edudownloads.azureedge.net/msdownloads/Microsoft-

EducationReimagined-Paper.pdf [Accessed on 1 June 2020].

18. Gauntlett, D. (2018), Making is connecting. The social power of creativity, from craft and knitting to digital everything, Cambridge: Polity press

19. Illich, I. (1971), Deschooling society, New York: Penguin books.

20. Gibbs, G. (2010), Dimensions of quality, York: The Higher Education Academy.

21. Gibbs, G. (2012), Implications of 'Dimensions of quality' in a market environment, York: The Higher Education Academy.

22. Jessop, T. (2020), "Let's lose the deficit language about online education", WonkHE, [Online] available at: https://wonkhe.com/blogs/lets-lose-the-deficitlanguage-about-online-education/ [Accessed on 3 June 2020].

23. Kleon, A. (2012), Steal like an artist. 10 thinks nobody told you about being creative, New York: Workman.

24. Kofinas, A., Bentley, Y., Minett-Smith, C. and Cao, G. (2017), "Block Teaching as the Basis for an Innovative Redesign of the PG Suite of Programmes in University of Bedfordshire Business School", in: $3^{\text {rd }}$ International Conference on Higher Education Advances, Valencia: Polytechnic University of Valencia Congress, pp. 713-725. http://dx.doi.org/10.4995/HEAd17.2017.5379

25. Mazur, E. (1997), Peer Instruction: A User's Manual. Upper Saddle River, NJ: Prentice Hall.

26. Nelson, R. (2018), Creativity Crisis. Towards a post-constructivist educational future. Clayton, Victoria: Monash University Publishing.

27. Nerantzi, C. (2017), Towards a framework for cross-boundary collaborative open learning in cross-institutional academic development, $\mathrm{PhD}$ thesis, Edinburgh: Edinburgh Napier University.

28. Nerantzi, C. and Hannaford, L. (2016), "Flipping the classroom using teams. A case study from Academic Development", in: Whatley, J. and Nerantzi, C. (eds.) (2016), Teaching with Team Projects in Higher Education, Santa Rosa, CA: Informing Science Press, pp. 119-130.

29. Nordmann, E., Horlin, C., Hutchison, J., Murray, J-A., Robson, L., Seery, M. K and MacKay, J. R. D. (2020), "10 Simple Rules for Supporting a Temporary Online Pivot in Higher Education", PsyArXiv, https://doi.org/10.31234/osf.io/qdh25

30. Penner, J. G. (1984), Why Many College Teacher's Cannot Lecture, Springfield: Charles C. Thomas.

31. Qamar, A. H. (2020), "Quarantined-at-home teaching experience: My e-learning plan and implementation", Journal of Teaching and Learning, Vol. 14. No.1, pp. 120-132, https://doi.org/10.22329/jtl.v14i1.6250

32. Quality Assurance Agency for Higher Education (QAA) (2020), Guidance: Building a taxonomy for digital learning, UK: Quality Assurance Agency for

International Journal of Management and Applied Research, 2020, Vol. 7, No. 2 
The Use of Peer Instruction and Flipped Learning to Support Flexible Blended Learning During and After the COVID-19 Pandemic

Higher Education, [Online] available at: https://www.qaa.ac.uk/news-

events/news/qaa-publishes-building-a-taxonomy-for-digital-learning [Accessed on 1 June 2020].

33. Ramsden, P. (2003), Learning to Teach in Higher Education, $2^{\text {nd }}$ ed., London: Routledge.

34. Schell, J. A. and Butler, A. C. (2018), "Insights From the Science of Learning Can Inform Evidence-Based Implementation of Peer Instruction", Frontiers in Education, Vol. 33, Article 33. https://doi.org/10.3389/feduc.2018.00033

35. Schell, J. A. and Mazur, E. (2015) "Flipped the chemistry classroom with Peer Instruction", in: García-Martínex, J. and Serrano-Torregrosa, E. (eds), Chemistry Education: Best Practices, Opportunities and Trends, Wiley-VCH, pp. 319-334. https://doi.org/10.1002/9783527679300.ch13

36. Scott, G. (2020), Can we plan for a socially distanced campus?, WonkHE, [Online] available at: https://wonkhe.com/blogs/can-we-plan-for-a-socially-distancedcampus/ [Accessed on 1 June 2020].

37. Tucker, B. (2012), "The flipped classroom: online instruction at home frees class time for learning", Education Next, Vol. 12, No. 1, pp. 82-83.

38. Telles-Langdon, D. M. (2020), "Transitioning university courses online in response to COVID-19", Journal of Teaching and Learning, Vol. 14, No. 1, pp.108-119. https://doi.org/10.22329/jtl.v14i1.6262

\section{Appendix}

Frameworks reviewed by Nerantzi (2017)

\begin{tabular}{|c|c|c|c|c|}
\hline $\begin{array}{l}\text { Year } \\
\text { Appeared }\end{array}$ & Framework & $\begin{array}{l}\text { Conceptual/ } \\
\text { Empirical }\end{array}$ & $\begin{array}{l}\text { Formal/ } \\
\text { Informal }\end{array}$ & Application \\
\hline 1971 & $\begin{array}{l}\text { Supported Open } \\
\text { Learning }\end{array}$ & Conceptual & Formal & Distance Learning \\
\hline 1985 & $\begin{array}{l}\text { Computer-Supported } \\
\text { Collaborative Learning }\end{array}$ & Conceptual & $\begin{array}{l}\text { Formal and } \\
\text { Informal }\end{array}$ & $\begin{array}{l}\text { Technology- } \\
\text { assisted Learning }\end{array}$ \\
\hline 1991 & Community of Practice & Empirical & Informal & Team Learning \\
\hline 2000 & $\begin{array}{l}\text { Community of inquiry } \\
\text { framework }\end{array}$ & Conceptual & Formal & Blended Learning \\
\hline 2002 & S-Stage model & Empirical & Formal & Online Learning \\
\hline 2009 & 3E Framework & Empirical & Formal & Blended Learning \\
\hline 2012 & $\begin{array}{l}\text { Online Collaborative } \\
\text { Learning Theory }\end{array}$ & Empirical & Formal & Online Learning \\
\hline 2013 & $\begin{array}{l}\text { 7Cs of the Learning } \\
\text { Design Framework }\end{array}$ & Conceptual & Formal & $\begin{array}{l}\text { Blended and } \\
\text { Online Learning }\end{array}$ \\
\hline 2014 & 5C Framework & Conceptual & $\begin{array}{l}\text { Formal and } \\
\text { Informal }\end{array}$ & Online Learning \\
\hline
\end{tabular}

International Journal of Management and Applied Research, 2020, Vol. 7, No. 2 